\title{
Risks, forecasting and tactical decision-making in integrated pest and disease management ${ }^{1}$
}

\author{
by R. A. DAAMEN and R. RABBINGE* \\ Research Institute for Plant Protection (IPO), P.O. Box 9060, \\ $6700 \mathrm{GW}$ Wageningen (Netherlands) \\ *Department of Theoretical Production Ecology (TPE), \\ Agricultural University Wageningen, P.O. Box 430, \\ 6700AK Wageningen (Netherlands)
}

\begin{abstract}
The uncertainty of pest and disease outbreaks and the associated damage (risk) may limit the adoption of integrated farming systems. This risk can be reduced by preventive practices and by a selective use of pesticides based on monitoring and forecasts. Whether forecasts based on agrometeorological data may reduce risk depends mainly on the strength of the weather dependency of the host and the parasite and whether outbreaks can be forecast accurately and in time to allow control action. Pests for which the weather only sometimes enables an outbreak, or which exhibit long incubation periods, are good candidates for forecasts based on weather. Epidemics of wheat diseases are discussed as an illustration.
\end{abstract}

\section{Introduction}

Arable farming in The Netherlands is very intensive. There are high inputs and there is a great dependence on pesticides to control pests and diseases. Pesticides are often regarded as an inevitable cultural method. However there seems to be a considerable waste of pesticides. Pesticides are not needed in all cases and a considerable reduction in their use is therefore possible. This is achieved in integrated farming by the adoption of preventive measures in combination with pesticide use only in those situations where the resistance of the agroecosystem fails to prevent a pest or disease outbreak in a specific field. If such corrections are often necessary, the preventive measures taken need to be reconsidered to increase the resistance of the agro-ecosystem.

Calendar spraying of pesticides is, from a viewpoint of pest management, a strategy with a low risk. The costs of pesticides and their date of application are known. In general this leads to high fixed costs and a low damage due to pests and diseases. If pesticide use is reduced, the uncertainty increases. Though pesticide costs are reduced, the damage due to primary pests and diseases increases and, because their epidemics vary from year to year and from field to field, the uncertainty on damage increases. To replace calendar spraying, damage and its variation has to be reduced by the adoption of preventive measures and mechanical and biological control methods in combination with a selective use of pesticides based on forecasts of the development of diseases and pests and associated damage. In addition to field-specific characteristics (such as cultivar resistance, fertilizer use, growth stage), agrometeorological knowledge especially may improve epidemiological forecasts and thus reduce the risk of outbreaks of pests and diseases by selective use of pesticides.

\footnotetext{
${ }^{1}$ Paper presented at the Joint WMO/EPPO/NAPPO Symposium on Practical Applications of Agrometeorology in Plant Protection, Firenze (IT), 1990-12-04/07.
} 


\section{Agrometeorological conditions and risk}

The significance of risk is illustrated by the occurrence of powdery mildew of winter wheat (Erysiphe graminis) in The Netherlands (Fig. 1). The prevalence of powdery mildew varies considerably between years. This variation is to a large extent due to environmental conditions. Agrometeorological and phytopathological knowledge may therefore improve epidemiological forecasts. The relationship between powdery mildew and wheat depends strongly on temperature at the seedling stage, when primary infections establish. In cold winters, E. graminis may die out due to frost, while when mild winters occur secondary infections may develop (Fig. 2).

Forecasts based on weather data therefore reduce risk and thereby reduce pesticide use considerably under circumstances where:

(1) the pest causes considerable damage in a certain area;

(2) the development of the pest depends strongly on weather, so that epidemics vary considerably between years;

(3) the forecasting period is long enough to allow control action.

\section{Application of criteria}

These criteria may be illustrated for the epidemics and control of eyespot (Tapesia yallundae, anamorph Pseudocercosporella herpotrichoides) in winter wheat in The Netherlands during 1974-86 as an example. Data are derived from the surveys of diseases and pests in winter wheat for which more than 100 commercial fields were surveyed each year. In these fields a system of supervised control was adopted. The disease (eyespot) attacks the stem bases of wheat, and may cause lodging and consequent damage. During the period 1974-84, about 12\% (SE 8\%) of fields were sprayed in May to control eyespot. This corresponds with an annual use of an average of $6000 \mathrm{~kg}$ of fungicides (a.i. $3000 \mathrm{~kg}$ carbendazim) in the 100,000 ha area of winter wheat in The Netherlands. The damage caused by the disease and the fungicide cannot be estimated, but is very low. The use, and cost, of eyespot fungicides is small compared with the total annual use of $200 \mathrm{t}$ of fungicides and insecticides in wheat and the production value of 400 million NLG. Thus,

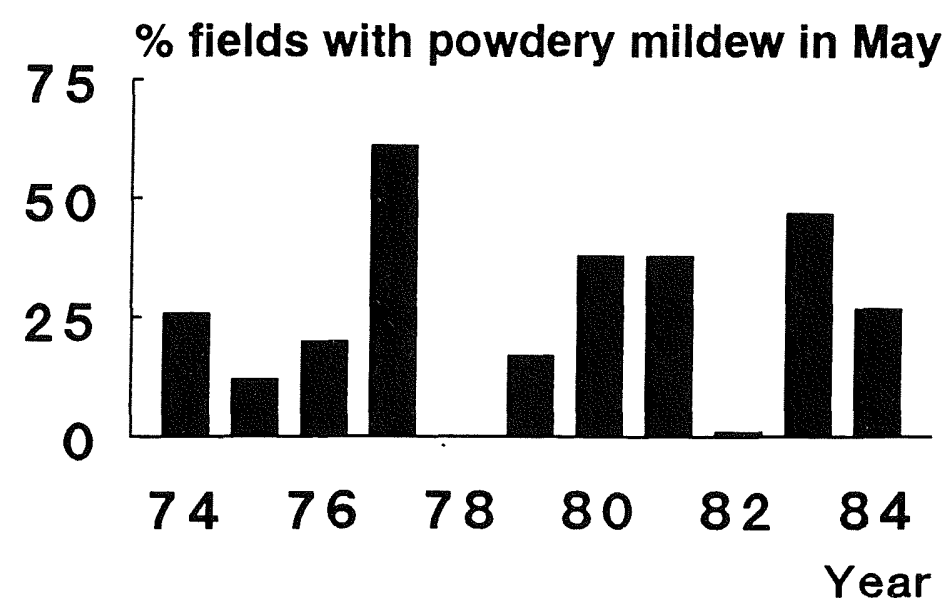

Fig. 1. Uncertainty: variation in annual prevalence of Erysiphe graminis on winter wheat in May during 1974-84 (1978 missing).

Incertitude: variation de l'incidence annuelle en mai d'E. graminis sur blé d'hiver en 1974-1984 (1978 manque). 


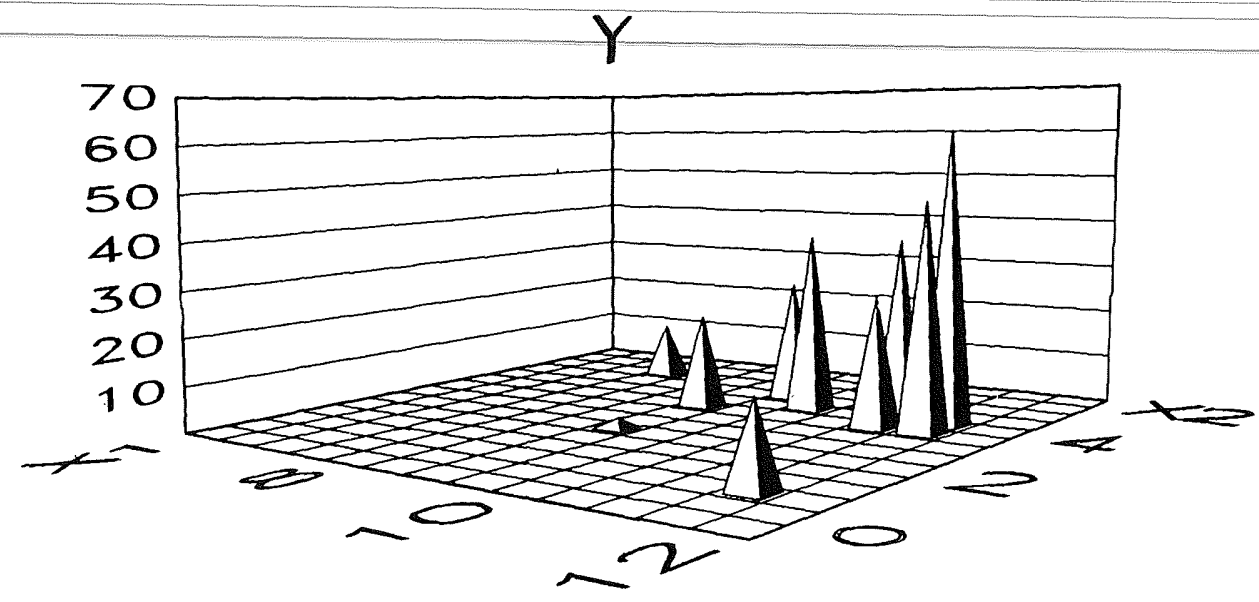

Fig. 2. Annual prevalence of Erysiphe graminis on winter wheat in May ( $\mathrm{Y}=\%$ of fields surveyed with powdery mildew), in relation to average temperature in October $\left(\mathrm{X}_{1},{ }^{\circ} \mathrm{C}\right)$ and average temperature over the months December-March $\left(\mathrm{X}_{2},{ }^{\circ} \mathrm{C}\right)$. Same data as in Fig. 1.

Incidence annuelle en mai d'E. graminis sur blé d'hiver ( $\mathrm{Y}=\%$ de parcelles avec oïdium), en fonction de la température moyenne en octobre $\left(\mathrm{X}_{1},{ }^{\circ} \mathrm{C}\right)$, ainsi qu'en décembre-mars $\left(\mathrm{X}_{2},{ }^{\circ} \mathrm{C}\right)$.

Regression: $\mathrm{Y}=-132+12 \mathrm{X}_{1}+10 \mathrm{X}_{2}\left(\mathrm{R}^{2}=0.83\right)$.

better forecasts of eyespot epidemics will not lead to a substantial reduction in the use of pesticides (criterion 1). However, it should be realised that the data were derived from fields under supervised control. In practice, $25 \%$ of the area on average is sprayed in May to control eyespot and if no advisory system is implemented, routine sprays may become common practice.

After a mild winter, more tillers are infected on average than after a severe winter (Fig. 3). This

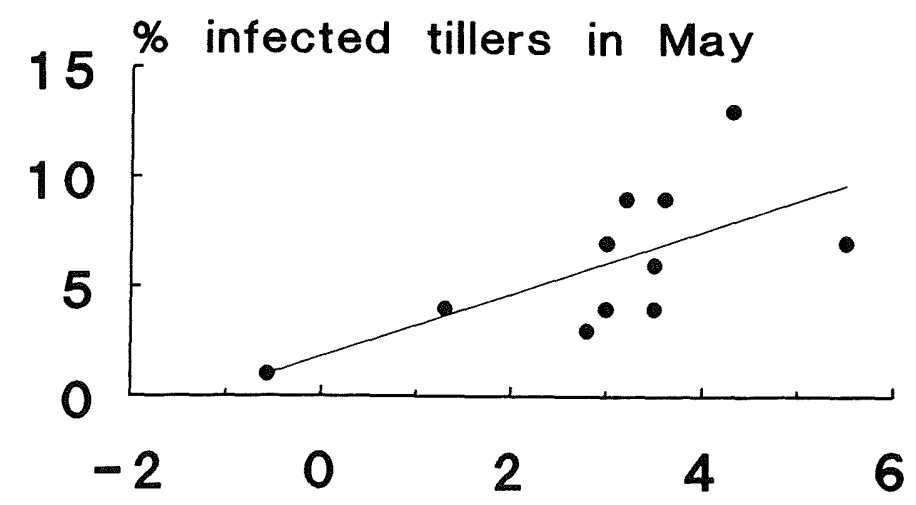

\section{Temperature December-February}

Fig. 3. Mean annual incidence of Pseudocercosporella herpotrichoides ( $\mathrm{Y}=\%$ infected tillers) in May in relation to average temperature $\left(\mathrm{X},{ }^{\circ} \mathrm{C}\right)$ over the months December-February. Survey fields, 1974-84. Incidence annuelle moyenne en mai de $P$. herpotrichoides ( $\mathrm{Y}=\%$ de talles infectées), en fonction de la température moyenne en décembre-février. Etude de 1974 à 1984.

Regression: $\mathrm{Y}=1.8+1.4 \mathrm{X}\left(\mathrm{R}^{2}=0.44\right)$. 


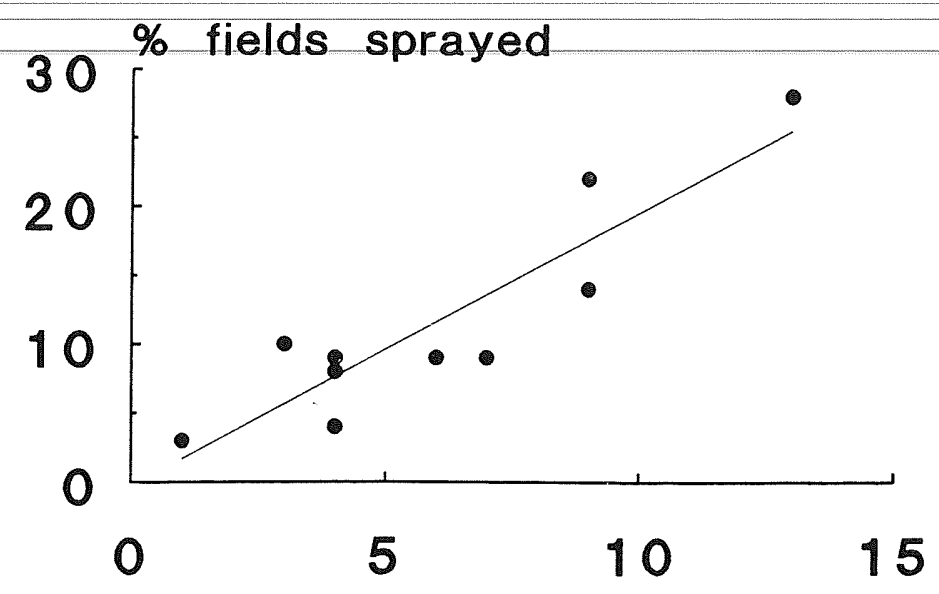

\section{$\%$ infected tillers in May}

Fig. 4. \% of winter wheat fields sprayed to control Pseudocercosporella herpotrichoides (Y), in relation to mean annual eyespot incidence in May (X=\% infected tillers). Survey fields 1974-84 (1978 missing). $\%$ de parcelles de blé d'hiver traitées contre $P$. herpotrichoides $(\mathrm{Y})$, en fonction de l'incidence moyenne de piétin-verse en mai (X=\% de talles infectées). Etude de 1974 à 1984 (1978 manque).

Regression: $\mathrm{Y}=-0.3+2.0 \mathrm{X}\left(\mathrm{R}^{2}=0.81\right)$.

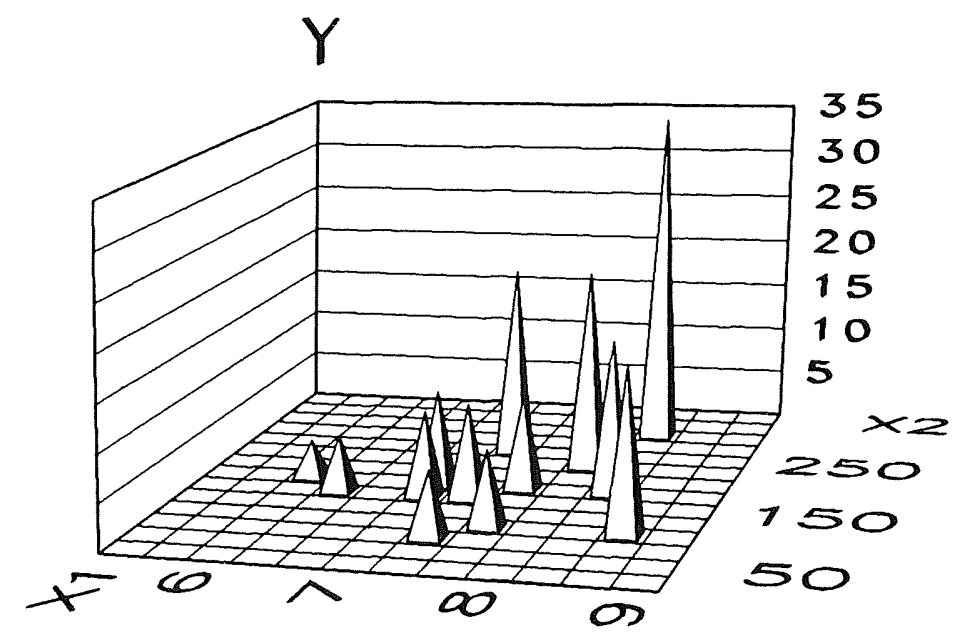

Fig. 5. Mean annual incidence of Pseudocercosporella herpotrichoides in July ( $\mathrm{Y}=\%$ infected tillers), in relation to mean temperature in April $\left(\mathrm{X}_{1},{ }^{\circ} \mathrm{C}\right)$ and cumulative precipitation during March, April and May $\left(\mathrm{X}_{2}, \mathrm{~mm}\right)$. Survey fields $1974-86$.

Incidence annuelle moyenne en juillet de $P$. herpotrichoides ( $\mathrm{Y}=\%$ de talles infectées), en fonction de la température moyenne en avril $\left(\mathrm{X}_{1},{ }^{\circ} \mathrm{C}\right)$ et des précipitations cumulées de mars, avril et mai $\left(\mathrm{X}_{2}, \mathrm{~mm}\right)$. Etude de 1974 à 1986.

Regression: $\mathrm{Y}=-49+6.3 \mathrm{X}_{1}+0.09 \mathrm{X}_{2}\left(\mathrm{R}^{2}=0.91\right)$. 
relation is not very clear. In practice, farmers inspect their fields in May and a spray is recommended if more than $15 \%$ of tillers are infected by $P$. herpotrichoides. The data from $1974-$ 84 show a relation between the average \% tillers infected in May and the \% fields sprayed (Fig. 4).

There was no correlation between \% tillers infected in May, or \% fields sprayed, and \% tillers infected in July. Instead, \% tillers infected in July was correlated with temperature during April and cumulative precipitation during March, April and May (Fig. 5). This is a well-known relation. Epidemics of eyespot strongly depend on weather and thus on year (criterion 2). This dependency may be forecast on the basis of weather data during March-May. In this way, the forecasting period is long enough to allow control action (criterion 3). Agrometeorological data may therefore improve forecasts considerably. In the advisory system EPIPRE, no weather data are used at the moment. If weather data are incorporated, the forecasts will be more reliable. Though eyespot is a minor problem in The Netherlands (criterion 1), this improvement may stimulate the adoption of the advisory system by farmers.

\title{
Weather, forecasting and advisory system
}

Historical data can reveal whether pest and disease epidemics fluctuate considerably between years. Detailed epidemiological knowledge is required to determine the agrometeorological factors which limit outbreaks and to quantify this relationship. A decision-oriented approach is then needed to incorporate this knowledge into a forecasting/advisory system to make pesticide use selective. Elements of such advisory systems are given in Table 1. Many advisory systems will contain a combination of several of the elements listed.

Agrometeorological data affects the elements listed and thus the decision process. Disease and pest management is often based on monitoring (element 1). By monitoring, the historical events in a specific field, past weather inclusive, are updated. The disease/pest itself is certainly the best agrometeorological and agro-ecological integrator available, and can partly replace agrometeorological data. This underlies the success of many management systems based on monitoring. Nevertheless, agrometeorological data may be used to determine the right moment of monitoring, thus reducing the total amount of observation time.

The forecasting period (element 2 ) is an important element of any forecasting/advisory model. If the period is too short, control actions can no longer be performed; if it is too long, the uncertainty of the forecast may become unacceptably high. Because the ultimate goal of forecasts is to avoid severe damage and financial loss, the host (crop) determines the forecasting period. As developmental processes of the host are especially sensitive to temperature and sometimes to daylength, agrometeorological knowledge may be very valuable in determining the forecasting period. Of course the development of pests and diseases (element 3 ) has to be forecast during this period. This depends strongly on weather and most studies concentrate on this

Table 1. Elements of forecasting/advisory systems

Eléments des systèmes de prévision et d'avertissement

\author{
1. Actualize state of field by disease/pest monitoring \\ 2. Determine forecasting period \\ 3. Forecast epidemic \\ 4. Forecast damage based on expected epidemic \\ 5. Determine forecast loss from expected product price \\ 6. Determine efficacy of control method \\ 7. Calculate costs of applying control method \\ 8. Evaluate expected costs and benefits of control action
}


aspect. The forecasts are used in advisory systems to evaluate damage and benefits of control, in order to optimize the profitability of a control action.

Damage relations are used to estimate the expected damage (element 4) from the forecast epidemics. Damage relations are presumably less affected by weather than are epidemiological relations. The product price (element 5) may partly depend on weather, especially when the amount and time in the year determine the price. The efficacy of the control method (element 6), whether chemical, biological or mechanical, depends on weather which affects both the initial effectiveness and the persistence of the control method. Recommended dosages of pesticides are usually high to ensure good efficacy even under bad weather conditions. Here again agrometeorological knowledge may reduce the amount of pesticides used.

\section{Taking actual weather into account}

The paradox is that many adivsory systems use economic injury levels without accounting for weather. By monitoring, the historical events in a specific field, including weather, are actualized. We may accordingly argue that past weather is redundant information. Moreover, future weather is unknown. The question then arises when and how we should incorporate weather data into advisory systems based on disease monitoring. A more exact approach is used here to discuss this question.

Three elements are important in forecasting epidemics: (1) the initial disease/pest intensity monitored $\left(\mathrm{Y}_{0}\right) ;(2)$ the forecasting period $(\mathrm{t}) ;(3)$ the rate of increase $(\mathrm{r})$. In EPIPRE, the forecasting period $(\mathrm{t})$ depends on the expected time for the crop to reach the early-dough growth stage. The rate of increase ( $r$ ) is the rate, averaged over years and adapted to the field-specific conditions, as mentioned in the introduction. The initial disease intensity $\left(\mathrm{Y}_{0}\right)$ is estimated by monitoring and to some extent integrates past weather. This initial intensity reflects visible symptoms at a certain time. All infections which took place within the time-span of one incubation period (i) before that time are not yet visible. The rate of increase (ri) by these not yet visible infections may be forecast on the basis of actual weather data. The most basic equation to forecast epidemics is the exponential growth equation, which is also used in EPIPRE. During periods of exponential growth, the disease intensity after the forecasting period $\left(\mathrm{Y}_{\mathrm{t}}\right)$ follows:

$$
Y_{\mathrm{t}}=\mathrm{Y}_{0} \cdot \mathrm{e}^{\mathrm{r}(\mathrm{t}-\mathrm{i})+\mathrm{ri}(\mathrm{i})} \text {. }
$$

From this one may derive that forecasts based on actual weather data may improve advice when: (1) the incubation period (i) is not short compared to the forecasting period (t); (2) the expected rate of increase (ri) due to infections during the time-span of one incubation period differs considerably from the average rate of increase (r). Thus diseases which exhibit long incubation periods (or long cold periods), and diseases where weather only sometimes enables infection and consequent disease development, are the best candidates for forecasts based on actual weather data.

\section{Conclusions}

Historical data on weather and occurrence of epidemics are of vital importance in identifying when and which agrometeorological factors limit epidemics. However, the absence of reliable weather forecasts often does not hamper reliable pest and disease forecasting based on agrometeorological data.

\section{Prévisions, risques et tactiques en lutte intégrée}

L'intensité des attaques par les ennemis des cultures ainsi que les dégâts occasionnés sont très variables, ce qui risque de décourager l'adoption de systèmes de production intégrée. Cette 
variabilité peut être réduite par la mise en oeuvre de mesures préventives, ainsi que par une utilisation sélective des pesticides à l'aide de systèmes de prévision et d'avertissement. La capacité des prévisions à diminuer les risques phytosanitaires dépend, dans le cas des systèmes basés sur des éléments météorologiques, du degré de l'influence de ces derniers sur la plant-hôte et sur le parasite, ainsi que de la précision des prévisions et des possibilités d'intervention rapide. Les organismes nuisibles pour lesquels les conditions météorologiques ne permettent qu'occasionnellement des attaques, ou qui manifestent une longue période d'incubation, se prêtent particulièrement bien aux systèmes météorologiques de prévision. L'article présente le cas des maladies du blé à titre d'exemple.

Риск, прогнозирование и тактика принятия решений в комплексной системе борьбы с вредителями и заболеваниями.

Изменчивость интенсивности вспышек заболеваний и массовой инвазии вредителей, а также наносимый ими ущерб (риск) могут явиться факторами, ограничивающими комплексные методы сельскохозяйственного производства. Возможные потери могут быть сокращены путем проведения предупредительных мероприятий и селективного применения пестицидов, опираясь на систему наблюдений и прогнозирования. Насколько прогнозирование, основанное на агрометеорологических данных, может снизить вероятность потерь, зависит главным образом от того, в какой степени погодные условия влияют на растение-хозяина и на самого вредителя, а также от возможности предсказания массовых вспышек достаточно точно и заблаговременно, с тем чтобы провести соотвествующие мероприятия. Вредители, массовое заселение которых нерегулярно зависит от погодных условий, или которые имеют длительные инкубационные периоды, особенно хорошо удовлетворяют требованиям прогнозов, основанных на метеорологических данных. В качестве примера приводятся случаи заболеваний пшеницы. 
